\title{
Formação continuada de professores da Educação Básica do Campo
}

Elizeni Belo da Silva ${ }^{1}$, Emerson Augusto de Medeiros ${ }^{2}$

\section{Resumo}

Este estudo tematiza a formação continuada de professores da Educação Básica do Campo. Objetiva compreender como se desenvolve a formação continuada de docentes dos anos iniciais do Ensino Fundamental de uma escola municipal, Assentamento Favela, Mossoró-RN. Em parâmetros metodológicos, ancora-se na abordagem qualitativa e se caracteriza como uma investigação de cunho exploratório e descritivo. Participaram do estudo duas professoras que lecionam em turmas multisseriadas dos anos iniciais do Ensino Fundamental situadas na escola em referência. Como técnica para a construção dos dados, utilizou-se questionário composto por dez questões abertas. Conclui-se, entre outros pontos, que as práticas de formação continuada vivenciadas pelas participantes da pesquisa não se alinham, em maior parte, à Educação do Campo, situada no texto como um movimento nacional de educação. No entanto, contribuem em parte para a qualificação do trabalho docente desenvolvido pelas professoras em sala de aula.

\section{Palavras-chave}

Formação continuada de professores. Educação Básica do Campo. Educação no Semiárido.

\footnotetext{
${ }^{1}$ Graduada em Educação do Campo pela Universidade Federal Rural do Semi-Árido, Rio Grande do Norte, Brasil. E-mail: elizenibelo@gmail.com.

${ }^{2}$ Doutor em Educação pela Universidade Estadual do Ceará, Brasil; professor efetivo do Departamento de Ciências Humanas da Universidade Federal Rural do Semi-Árido, Rio Grande do Norte, Brasil; líder do Grupo de Pesquisa Formação Docente (UFERSA); membro dos Grupos de Pesquisa Educação, Memórias, (Auto) Biografias e Inclusão (UERN); Laboratório de Práticas, Estudos e Pesquisas em Formação de Professores Universidade e Escolas de Educação Básica (Laconex@o/UFPB) e Educação, Discursos e Sociedade (UFERSA). E-mail: emerson.au @ hotmail.com.
} 


\title{
Continuing training of Basic Education teachers in the field
}

Elizeni Belo da Silva ${ }^{3}$, Emerson Augusto de Medeiros ${ }^{4}$

\begin{abstract}
This study aims at investigating the continued training of basic education teachers in the countryside. Its objective is to understand the development of the continuous teacher's training in the early years of elementary school of a municipal school, in a Favela settlement, in Mossoró, State of Rio Grande do Norte, Brazil. It is a qualitativebased research and it is characterized as an exploratory and descriptive investigation. Two teachers in multi-grade classes of the initial years of elementary level in this school participated in the research. As data collection technique, was used a questionnaire composed of ten open questions. It is concluded, among other points, that the continuing education practices experienced by the research participants are not, mostly, in accordance with the Countyside Education, situated in the text as a national education movement. However, they contribute, partially, with the qualification of the teaching work carried out by teachers in the classroom.
\end{abstract}

\section{Keywords}

Continuing teacher training. Basic Education in the field. Education in the Semiarid.

\footnotetext{
${ }^{3}$ Graduated in Rural Education, Federal Rural University of the Semi-Arid, State of Rio Grande do Norte, Brazil. E-mail: elizenibelo@gmail.com.

${ }^{4} \mathrm{PhD}$ in Education, State University of Ceará, State of Ceará, Brazil; effective professor at the Department of Human Sciences at the Federal Rural University of the Semi-Arid, State of Rio Grande do Norte, Brazil; leader of the Teacher Training Research Group (UFERSA); member of the Education, Memories, (Auto) Biographies and Inclusion Research Groups (UERN); Laboratory of Practices, Studies and Research in Teacher Education University and Schools of Basic Education (Laconex @ o / UFPB) and Education, Discourses and Society (UFERSA). E-mail: emerson.au @ hotmail.com.
} 


\section{Introdução}

Para Medeiros (2019), entre o final do século 20 e início do século 21, houve uma maior atenção, por parte da sociedade, para a formação dos professores da Educação Básica que lecionam no campo. Segundo o autor, isso se deu, entre outros aspectos, por questões legais e políticas (especialmente em virtude da promulgação da segunda Lei de Diretrizes e Bases da Educação Nacional, Lei no 9.394, de 20 de dezembro de 1996), bem como pelo entendimento de que não há como se pensar na qualidade educacional dos povos do campo sem valorizar a formação docente.

Este estudo, seguindo a compreensão de que a formação dos professores da Educação Básica do campo é um dos aspectos centrais para a melhoria da qualidade educacional de suas populações, tem como tema central a "formação continuada de docentes da Educação Básica do campo". Ancora-se na seguinte questão investigativa: como vem se desenvolvendo a formação continuada de professores dos anos iniciais do Ensino Fundamental de uma escola municipal ${ }^{5}$, Assentamento Favela, Mossoró-RN?

Em relação ao objetivo da investigação, enfatizamos "compreender como se desenvolve a formação continuada de professores dos anos iniciais do Ensino Fundamental de uma escola municipal, Assentamento Favela, Mossoró-RN”. Para nós, pesquisadores da área de Educação, o estudo sobre a formação continuada no contexto referendado é carregado de sentidos, uma vez que se relaciona com o nosso contexto de vida na condição de sujeitos que trabalharam (como profisssionais da educação) ou viveram no campo.

Em parâmetros metodológicos, apoiamo-nos na abordagem qualitativa de pesquisa. Além disso, referendamos que o estudo se tipifica como exploratório e descritivo. Vale reafirmar que a pesquisa teve como lócus de investigação uma escola municipal circunscrita ao Assentamento Favela, Mossoró - RN. Do estudo, participaram duas professoras ${ }^{6}$ que lecionam em turmas multisseriadas do $1^{\circ}$ ao $5^{\circ}$ ano do Ensino Fundamental ${ }^{7}$.

\footnotetext{
${ }^{5}$ Registramos que, independentemente de termos a autorização para a divulgação do nome da escola, bem como dos sujeitos que participaram do estudo, via Termo de Consentimento Livre e Esclarecido (TCLE), preferimos não fazê-los no texto. Esse aspecto se alinha à Resolução CNS n⿳ 510, de 07 de abril de 2016, que apresenta orientações/parâmetros para a pesquisa com seres humanos (BRASIL, 2016).

${ }^{6}$ As duas professoras possuem formação inicial na licenciatura em Pedagogia. Ambas atuam na área de educação há mais de 20 anos, são docentes efetivas do sistema municipal de educação. Destacamos que não residem no Assentamento Favela, Mossoró-RN. Elas se deslocam diariamente do perímetro urbano para o campo.

${ }^{7}$ As duas professoras são as únicas docentes que lecionam na instituição, aspecto que justifica suas participações no estudo. A escola em que lecionam oferta somente os anos iniciais do Ensino Fundamental.
} 
Para a construção dos dados, organizamos um questionário composto por dez (10) questões abertas, o qual foi projetado a partir de três eixos temáticos que dialogam, centralmente, com o objetivo da investigação, a saber: (1) práticas de formação continuada; (2) formação continuada e trabalho docente no campo; e (3) limites da formação continuada de professores da Educação Básica do campo.

Após discutirmos, nessa breve introdução, os aspectos que circundam o estudo, enfatizamos que sistematizamos o restante do texto, o qual apresentará a pesquisa, em mais três seções. No primeiro momento, com base na revisão da literatura nacional e internacional, discutimos acerca de alguns conceitos sobre a formação continuada de professores. Na segunda seção, debatemos, sob a óptica das professoras participantes da pesquisa, como se desenvolve a formação continuada de docentes da Educação Básica do campo, considerando os eixos temáticos apresentados no parágrafo anterior e a realidade investigada. Na última seção, tecemos as considerações finais, enfatizando a necessidade de valorização da Educação do Campo nas propostas de formação continuada destinadas aos docentes que atuam em espaços no campo.

\section{Formação continuada de professores da Educação Básica: alguns conceitos}

Destacamos que a palavra "formação" é originária do latim formare, que quer dizer "a forma de ser". De acordo com Febre (1995 apud AMADOR, 2019, p. 95), "formar é mais ontológico do que instruir ou educar: na formação, é o próprio ser que está em causa da sua forma". No que tange à palavra "continuada", ela vem do verbo (também do latim) continuare, que "evoca prosseguir, dar seguimento, prolongar, permanecer sem desistência" (RIBEIRO, 2005 apud AMADOR, 2019, p. 89), o que traz a ideia de continuidade, algo que não pode ser interrompido.

Conforme o pensamento de Ribeiro (2005 apud AMADOR, 2019), a formação continuada é fundamental aos professores, pois o termo "continuada" significa, segundo registramos, dar continuidade aos estudos. Compreendemos, portanto, que se tornar um professor é um processo de longa duração, não tem fim, sendo um processo contínuo de aprendizagens durante todo o percurso de sua trajetória na área educacional (GARCIA, 2009). Partindo dessas afirmações, complementamos que a formação docente é "uma contínua caminhada dos profissionais da educação, em cujo caminhar atuam todas as suas dimensões individuais e coletivas de caráter histórico, biopsicossocial, político, cultural, próprias de 
seres integrais e autores de sua própria formação" (ALVORADO-PRADA; FREITAS; FREITAS, 2010, p. 370).

Com essas considerações, validamos que os educadores que continuam sua formação constroem novos conhecimentos, conceitos acerca da educação e práticas de ensino, partindo daquilo que já têm, ampliando, assim, o seu desenvolvimento (NÓVOA, 1992; GARCIA, 2009; IMBERNÓN, 2010). Segundo Amador (2019, p. 156), “podemos considerar que a FCP [formação continuada de professores] é uma prática que acompanha toda a carreira profissional dos docentes [...] preparando-os individual e coletivamente". Ainda com relação à formação continuada, Gatti e Barretto (2009, p. 203) afirmam:

Nesta concepção de formação como um contínuo ao longo da vida profissional, o conceito subjacente é o de desenvolvimento profissional. $\mathrm{O}$ processo de formação é definido como um movimento orientado a responder aos diversos desafios que se sucedem no que se poderia identificar como diferentes fases da vida profissional: o início da carreira, o processo de desenvolvimento e os tempos mais avançados em que o professor consolida sua experiência profissional.

A formação continuada docente abrange o andamento da profissão, o crescimento, os desafios de diferentes naturezas que emergem na vida dos professores, na sociedade, na escola, na educação, entre outros (NÓVOA, 1992). Assim, a formação continuada se faz também como um aprimoramento, modificando a atuação profissional do docente. Isto é, se constitui por etapas que ampliam/(re)significam a vida pessoal e profissional dos professores. Nos termos de Dalben (2004, p. 8):

A formação continuada não pode ser concebida apenas como um meio de acumulação de cursos, palestras, seminários, de conhecimentos ou técnicas, mas um trabalho de reflexividade crítica sobre as práticas e de construção permanente de uma identidade pessoal e profissional em interação mútua.

Para Alvorado-Prada, Freitas e Freitas (2010), o desenvolvimento humano acontece durante o desenvolvimento da aprendizagem, a qual está inter-relacionada a diferentes situações e contextos, ou seja, se faz de forma híbrida. A formação faz parte do processo de desenvolvimento humano e profissional. Nesse sentido, a formação continuada de professores pode ser pensada também como um dispositivo que ajuda aos professores no processo de ensino e de aprendizagem de seus estudantes, na procura de novas informações teóricometodológicos para o incremento profissional e a mudança de suas técnicas pedagógicas. No entanto, acrescentando a essa afirmativa, Alvorado-Prada, Freitas e Freitas (2010, p. 375) 
relatam que: "a formação continuada é frequentemente entendida como 'capacitação' e até como 'treinamento', 'reciclagem' e outras conotações”.

De modo diferente, pensamos que a formação continuada deve se exercer com boa fundamentação teórico-prática para que possa atender às condições necessárias de averiguar criticamente a realidade em que o docente está inserido, sobre a qual poderá agir com intervenções, visando transformá-la (FREIRE, 1996).

Segundo Pimenta e Ghedin (2002), a formação continuada deve valorizar os professores e as escolas como capazes de pensar, de articular os saberes científicos, os saberes pedagógicos e os saberes de experiência na construção e na proposição das transformações necessárias às práticas escolares e às formas de organização dos espaços de ensinar e de aprender. Dessa maneira, oferecer uma formação continuada voltada para as práticas em sala de aula proporciona melhor aprendizagem aos estudantes e também aos professores. Além disso, permite que eles (os professores) conheçam o seu próprio trabalho pedagógico.

Ao término dessas considerações, organizamos alguns conceitos sobre a formação continuada de professores da Educação Básica a partir de autores que discutem o tema. Vejamos o Quadro 1:

Quadro 1 - Conceitos de formação continuada de professores

\begin{tabular}{|l|l|}
\hline \multicolumn{1}{|c|}{ Autores } & \multicolumn{1}{|c|}{ Conceitos: } \\
\hline Alvorado-Prada, Freitas e Freitas (2010) & $\begin{array}{l}\text { A formação continuada é um processo no qual os } \\
\text { professores devem sempre buscar atualização } \\
\text { para manter uma educação de qualidade. Isso } \\
\text { permite estar com os conhecimentos atualizados } \\
\text { para ensinar aos estudantes. Desse modo, a } \\
\text { formação continuada é um instrumento } \\
\text { importante para auxiliar os docentes na prática } \\
\text { educativa e para melhorar sua prática } \\
\text { pedagógica. }\end{array}$ \\
\hline Gatti (2003) & $\begin{array}{l}\text { É um processo em que ocorre um aprendizado } \\
\text { constante. Nele, o professor busca uma } \\
\text { reavaliação do saber, ou seja, busca ressignificar } \\
\text { continuamente sua aprendizagem. }\end{array}$ \\
\hline Furtado (2015) & $\begin{array}{l}\text { É um processo que permite intensas reflexões } \\
\text { sobre crenças, valores e atitudes. Dessa maneira, } \\
\text { contribui ao desenvolvimento profissional do } \\
\text { docente. }\end{array}$ \\
\hline Amador (2019) & $\begin{array}{l}\text { É um percurso que se estende por toda a } \\
\text { trajetória profissional dos docentes, pois a a } \\
\text { formação é desde a inicial até a sua continuação. } \\
\text { A formação continuada contribui para melhorar a }\end{array}$ \\
\hline Rev. Ed. Popular, Uberlândia, v. 20, n. 1, p. 56-76, jan.-abr. 2021.
\end{tabular}




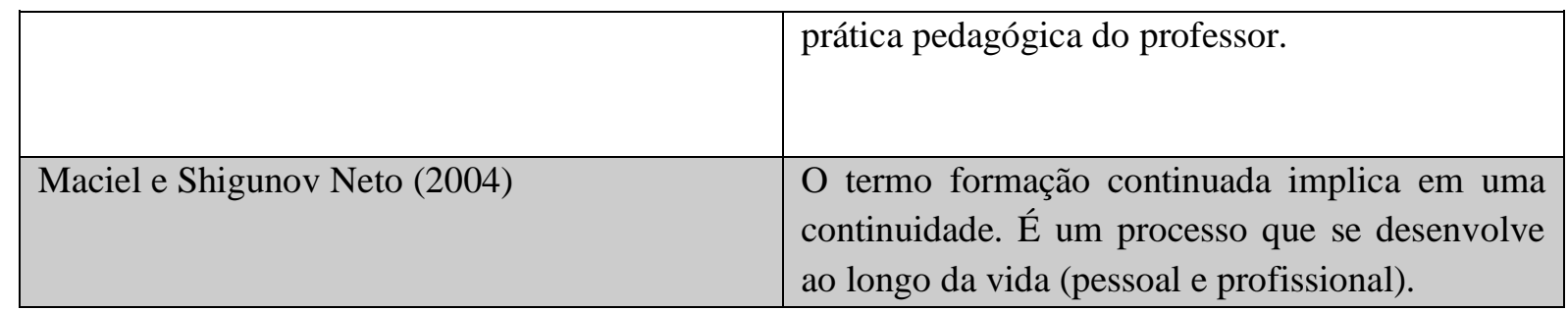

Fonte: Os autores (2020) com base em Gatti (2003), Maciel e Shigunov Neto (2004), Alvorado-Prada, Freitas e Freitas (2010), Furtado (2015) e Amador (2019).

Mediante leitura do Quadro 1, entendemos que a formação continuada é todo o processo vivenciado no decorrer da formação docente (seja essa no início, no meio ou no fim da carreira profissional do professor), pois esse profissional deve estar sempre buscando se atualizar para melhor desenvolver suas ações profissionais e, principalmente, pedagógicas.

\section{Formação continuada de docentes de uma escola municipal, Assentamento Favela, Mossoró-RN: a óptica das professoras}

Esta seção tem como intenção expor a análise acerca dos resultados construídos na pesquisa sobre o tema "formação continuada de docentes da Educação Básica do campo". Ditas essas palavras, as considerações arroladas se endereçaram ao questionário, composto por 10 (dez) questões abertas, o qual foi utilizado como técnica de construção dos dados. Lembramos que a análise validou os eixos temáticos enfatizados na pesquisa, a saber: (1) práticas de formação continuada; (2) formação continuada e trabalho docente no campo; e (3) limites da formação continuada de professores da Educação Básica do campo. Pontuamos que cada eixo temático se associou ao objetivo do estudo. Ressaltamos que as afirmações das participantes do estudo, dispostas no questionário, foram fielmente transcritas para o presente texto.

\section{Práticas de formação continuada}

Nesse momento, descrevemos as considerações relacionadas ao primeiro eixo temático projetado para a pesquisa, intitulado de "práticas de formação continuada". Para isso, organizamos três questões abertas, com o intuito de obtermos reflexões ao objetivo demarcado à investigação.

$\mathrm{Na}$ literatura acadêmica, a formação continuada é destacada como de grande importância para a atuação profissional do docente. A partir dela, os professores, em seu 
exercício profissional, podem desenvolver reflexões a respeito de suas práticas educativas e pedagógicas, ou seja, do seu trabalho na educação (GATTI; BARRETTO, 2009). Nesse lastro, a primeira questão pontuada no questionário, utilizado como técnica para a construção dos dados, diz respeito ao entendimento das docentes, participantes da pesquisa, acerca da formação continuada docente. Atentemo-nos aos registros das professoras:

É o processo permanente de aperfeiçoamento dos saberes necessários à atividade docente, realizado ao longo da vida profissional, com o objetivo de assegurar uma ação docente efetiva que promova aprendizagens significativas empregadas em sala de aula (Docente "A", Escola Municipal, Assentamento Favela, Mossoró-RN, 2019).

São formações ofertadas para capacitar os professores, para que possamos sempre estar preparados e atualizados para desenvolver atividades que tragam novas metodologias no processo de ensino-aprendizagem ${ }^{8}$ (Docente "B”, Escola Municipal, Assentamento Favela, Mossoró-RN, 2019).

As participantes do estudo consideram que a formação continuada é de fundamental importância para a atuação docente, haja vista que é a partir da formação continuada que há o aprimoramento de novas técnicas de ensino significativas para o trabalho docente em sala de aula, incluindo novas metodologias que qualifiquem os processos de ensino e de aprendizagem. A Docente "A" ressalta que a formação continuada tem por objetivo assegurar novas aprendizagens significativas para serem empregadas no contexto de trabalho. A Docente "B", por sua vez, afirma que a formação continuada é ofertada com a intenção de manter os professores atualizados na educação.

De forma geral, vemos que os entendimentos sobre a formação continuada das duas docentes se aproximam e se distanciam. Em relação à Docente "A", ela afirma, ainda, na nossa interpretação, que além de possibilitar a construção de conhecimentos para atuação docente em sala de aula, a formação continuada amplia os saberes necessários para a vida profissional (o que envolve a atuação na educação de maneira geral). A Docente "B", também validando o pensamento de que a formação continuada soma para o trabalho docente em sala de aula, a entende como uma prática de "capacitação", limitando-se, nesse sentido, à participação dos docentes em cursos de formação, o que não compreendemos ser dessa forma.

Seguindo o raciocínio de Amador (2019), conforme apresentamos anteriormente, a formação continuada dos professores da Educação Básica pode ser considerada como um

\footnotetext{
${ }^{8}$ Esclarecemos, novamente, que os registros apresentados no questionário foram transcritos para o texto tal como se encontraram no documento (o questionário). Fizemos pequenas correções linguísticas, na intenção de qualificar, textualmente, os registros das professoras.
} 
processo contínuo de aprimoramento e construção de diferentes saberes que, por consequência, se refletem nas ações profissionais e pessoais dos professores. Ocorre ao longo de suas trajetórias na educação, não se reduzindo a cursos de capacitação. Ela está atrelada a qualquer ação com objetivos intencionais que amplie o leque reflexivo dos docentes.

A segunda questão elencada no questionário indagou se as participantes do estudo vivenciaram/vivenciam a formação continuada em suas trajetórias na área educacional. Sobre isso, elas afirmam:

Sim, vivencio formação continuada em Atendimento Educacional Especializado - AEE. Como professora de AEE, essa formação tem me aprimorado nas minhas práticas pedagógicas de inclusão e aprendizagens para meus alunos (Docente "A", Escola Municipal, Assentamento Favela, Mossoró-RN, 2019).

Sim, participo de capacitações que auxiliam nas diversas áreas como: a construção de cisternas, alimentação saudável, escola da terra e outros que nos orientam para melhor desenvolvermos nossas atividades em sala de aula (Docente "B”, Escola Municipal, Assentamento Favela, Mossoró-RN, 2019).

Percebemos, a partir dos registros elucidados, que as professoras vivenciaram/vivenciam a formação continuada, e que ela tem proporcionado experiências fundamentais para o aprimoramento de seu trabalho na educação. A Docente "A" alude que a formação continuada vivida por ela se endereça ao âmbito da educação inclusiva, com o curso sobre o Atendimento Educacional Especializado - AEE. A Docente "B" destaca outros motes, a exemplo de "capacitações sobre cisternas, alimentação saudável, escola da terra", entre outros.

Nos dois registros, aparecem temas importantes à Educação Básica. O tema elencado pela Docente "A" é essencial para a atuação docente na educação no país. Em referência aos temas abordados pela Docente "B”, também enfatizamos sua relevância, pois comungam com temas que se associam ao contexto profissional em que ela atua - a Educação do Campo e a Educação no Semiárido.

Acreditamos que essa realidade favorece a construção de práticas educativas e pedagógicas mais conscientes e emancipatórias no local em que elas trabalham. A formação continuada, concebida por esse ângulo, nos dizeres de Alvorado-Prada, Freitas e Freitas (2010), redefine a identidade profissional das professoras, haja vista que pode, em cada vivência, trazer novos sentidos e significados sobre o ato de educar com base nas especificidades atentadas na formação vivida. 
Em relação à última questão referente ao eixo temático em discussão, questionamos se a formação continuada vivida por elas se deu de forma voluntária, a partir de suas necessidades profissionais e pessoais, ou se aconteceu/acontece por demandas institucionais, oriundas de ações da instância municipal a que pertencem profissionalmente. Elas declaram:

A formação continuada foi realizada tanto da demanda da instituição, como também pelo sistema educacional municipal (Docente "A", Escola Municipal, Assentamento Favela, Mossoró-RN, 2019).

A maioria foi por iniciativa da instituição, por parte do sistema educacional municipal (Docente "B”, Escola Municipal, Assentamento Favela, Mossoró$\mathrm{RN}, 2019)$.

Consta na LDB/1996, que é obrigação dos sistemas educacionais (federal, estaduais e municipais) promoverem a formação de seus docentes (BRASIL, 1996). Pelo que registraram as participantes da pesquisa, percebemos que essa demanda é, em parte (na nossa interpretação), cumprida pela instância municipal da qual são profissionais da Educação.

Não podemos nos esquecer de que, na atual LDB, a formação continuada dos professores foi colocada em pauta, justamente porque se admitiu que a formação docente é um dos mecanismos que contribui para elevar a qualidade educacional brasileira. Freitas (2007, p. 34) acrescenta "Definidos como prioridade, os programas de formação continuada, na nova LDBEN 9.394/96 [...], foram concebidos como mecanismos fundamentais para promover mudanças efetivas tanto na qualificação dos profissionais do ensino, quanto nos processos de aprendizagem".

Se pensarmos pela lente de que é a formação continuada que contribuirá, sozinha, para a melhoria da qualidade da educação no país, atribuiremos aos professores uma grande responsabilidade ao seu trabalho docente. Sabemos que há inúmeros limites, internos e externos às instituições escolares, que impossibilitam a melhoria da educação. Assim, não podemos resumir aos professores, tal como diz a LDB, a responsabilidade pelo que há de déficit educacional.

Ainda acerca dos registros das professoras, alertamos que não sabemos se a formação continuada que vivenciaram/vivenciam partiu de problemas da prática educacional local, a partir de diagnósticos desenvolvidos pelo poder público municipal, ou se foi projetada sem conexão com demandas da instituição em que trabalham. As professoras nos permitem o entendimento de que, em parte, a formação continuada é oriunda das demandas da instituição. Sobre isso, avaliamos que, independentemente de como foi projetada, é necessário que atenda 
às circunstâncias e problemas educativos que os docentes experienciam em seu cotidiano laboral.

De maneira conclusiva, evidenciamos que a formação continuada das professoras, participantes da pesquisa, acontece por meio de práticas de formação vinculadas a diferentes cursos desenvolvidos pela esfera municipal responsável pelo contexto educacional em que elas atuam.

\section{Formação continuada e trabalho docente no campo}

Nesta subseção, abordamos o segundo eixo temático pensado para o estudo Formação continuada e trabalho docente no campo. Para concretizá-lo na pesquisa, organizamos um conjunto de três questões abertas que, igualmente como as questões apresentadas no eixo temático anterior, intentam somar ao objetivo desta investigação.

Como primeira questão a explanarmos no momento, indagamos às professoras se as práticas de formação continuada vivenciadas por elas se desenvolveram/desenvolvem na Escola (espaço em que trabalham) ou em outros locais. Além disso, complementamos a respeito de quais sujeitos participaram/participam (professores da rede municipal, estadual, privada, entre outros) da formação experienciada. Na mesma questão, procuramos saber ainda se há incentivos da rede municipal de educação, da qual são profissionais efetivas, para que elas participem. Seus registros são esclarecedores:

Em outros locais da rede municipal, com os professores do município, o CADV [Centro de Apoio à Pessoa com Deficiência Visual] e o CAS [Centro de Apoio ao Surdo]. A rede municipal está sempre promovendo formação continuada em diversas áreas de conhecimento para os seus professores (Docente "A", Escola Municipal, Assentamento Favela, Mossoró-RN, 2019).

A maioria em outros espaços educacionais, tais como: UFERSA [Universidade Federal Rural do Semi-Árido], IFRN [Instituto Federal de Educação, Ciências e Tecnologia do Rio Grande do Norte], SENAI [Serviço Nacional de Aprendizagem Industrial], entre outros, sempre com a participação com professores da rede municipal, como também de outras instituições estaduais e federais" (Docente "B", Escola Municipal, Assentamento Favela, Mossoró-RN, 2019).

\footnotetext{
9 As docentes não declaram se há algum incentivo para que elas vivenciem a formação continuada, mas subentendemos que sim. O incentivo seria uma forma de motivação que a escola (por meio da gestão) trabalha com seus profissionais. Esse entendimento foi construído por meio de conversas informais com as participantes do estudo. No entanto, não conseguimos informações sobre a natureza do incentivo que recebem.
} 
Com as considerações das docentes, identificamos que a formação continuada experienciada por elas acontece em outros espaços, para além da escola. Dos momentos, participam/participaram os professores da rede municipal e também de outros contextos. Em análise a essas considerações, Imbernón (2010) aclara que desenvolver a formação continuada dos professores nos próprios espaços em que trabalham é essencial para o conhecimento (e em consequência, a solução) de problemas educacionais das instituições. No entanto, na lógica apresentada pelas professoras participantes da pesquisa, a formação continuada vivida por elas, para além da escola, é muito importante, haja vista que permite o diálogo e a construção de conhecimentos e saberes com docentes de realidades diversas. Pensamos que experienciar diferentes lugares de formação (na escola, em centros educacionais especiais, em faculdades e universidades) amplia o horizonte reflexivo dos docentes. Sobre isso, Pimenta e Lima (2006, p. 20) salientam:

Os lugares das práticas educativas, as escolas e outras instâncias existentes num tempo e num espaço, são o campo de atuação dos profissionais (os já formados e os que estão em formação). O conhecimento e a interpretação desse real existente serão o ponto de partida dos cursos de formação, uma vez que se trata de possibilitar aos [...] professores as condições e os saberes necessários para sua atuação profissional.

Entendemos que os diferentes espaços, com sujeitos diversos, são fundamentais para a construção da identidade profissional do professor. Com as professoras, acreditamos que esses lugares onde se formam proporcionam trocas de conhecimentos sobre seus contextos de trabalho, bem como experiências pessoais de vida, suas angústias e êxitos, entre outros.

$\mathrm{Na}$ continuidade da análise, a segunda questão do referido eixo temático auferiu a respeito de se elas consideram que as práticas de formação experienciadas contribuem para a sua atuação docente na escola em que lecionam. Observemos seus relatos textuais:

Sim, possibilitando refletir nossas ações e práticas pedagógicas de maneira a atender às necessidades e especificidades dos educandos (Docente "A", Escola Municipal, Assentamento Favela, Mossoró-RN, 2019).

Acredito que sim, pois nos orienta a vislumbrar novas metodologias para melhor desenvolver nosso trabalho no processo de ensino-aprendizagem, com as quais podemos trabalhar um tema de diversas formas (Docente "B", Escola Municipal, Assentamento Favela, Mossoró-RN, 2019). 
Analisando os registros das participantes do estudo, entendemos que a Docente "A" valida que a sua formação continuada contribui para o seu trabalho docente, pois possibilita refletir sobre as ações e as práticas pedagógicas, atendendo às necessidades e às especificidades de seus estudantes. A Docente "B" acredita que sim, já que a formação continuada a orienta a desenvolver novas metodologias para que ocorra um bom desenvolvimento do processo de ensino e de aprendizagem de seus discentes. Relata também que a formação continuada a possibilita trabalhar um tema de diversas maneiras, caminhando, no nosso entendimento, para uma prática docente com caráter dialógica e interdisciplinar.

Para Tardif (2010), o trabalho docente configura-se como o trabalho desenvolvido pelo profissional da educação, necessitando de uma formação adequada à função exercida. Assim, exige-se saberes de natureza múltipla - saberes da formação profissional, saberes disciplinares, saberes curriculares e saberes experienciais. O professor não ensina o que não sabe (FREIRE, 1996). Pelos relatos das professoras, afirmamos que a formação continuada, somando-se ao trabalho desenvolvido na escola com seus estudantes, tem contribuído para o crescimento dos sujeitos que participam dos processos educativos. A formação continuada, nesse sentido, tem-se feito como elemento de transformação dos participantes da educação professoras e estudantes.

A última questão que desenvolvemos, para esse eixo temático, sugere às professoras que registrem práticas pedagógicas desenvolvidas na escola, as quais são oriundas de contribuições da formação continuada experienciada por elas. Obtivemos as seguintes afirmações:

Um maior contato com a tecnologia, como aliada no processo de aprendizagem fazendo parte da rotina escolar, por meio de atividades lúdicas, criativas, como jogos educativos, inclusão, autonomia do educando e uma melhor habilidade em trabalhar a interdisciplinaridade (Docente "A", Escola Municipal, Assentamento Favela, Mossoró-RN, 2019).

Apresentação de trabalhos (seminários); artes dramáticas (dramatização); aulas-passeio (Docente "B", Escola Municipal, Assentamento Favela, Mossoró-RN, 2019).

Com essa questão, as docentes apresentaram diferentes técnicas de ensino que foram despertadas em suas práticas pedagógicas, o que se associa ao seu trabalho docente na sala de aula a partir das vivências na formação continuada. O registro da Docente "A" enfatiza o trabalho com as tecnologias de informação e comunicação na educação e a interdisciplinaridade. 
Para Kenski (2013), é imperioso o trabalho educacional com as tecnologias da informação e comunicação. Segundo a autora, vivemos em uma rede de informações que, o tempo todo, nos permite conhecer novos horizontes. Os professores devem se apropriar, em sua prática pedagógica, de elementos de cunho tecnológico atual. Em relação à interdisciplinaridade, Medeiros (2018), tal como Kenski (2013), afirma que, com as mudanças sociais no último século, não há como pensar o trabalho educativo sem o caráter interdisciplinar. A interdisciplinaridade, nos termos do autor, é uma demanda/necessidade ao ensino contemporâneo.

No que toca à Docente "B", ela detalha mudanças na dinâmica de suas aulas, acrescentando o trabalho com seminários, com dramatização e aulas-passeio. Rever nossos caminhos na educação é transformar nosso modo de ser e de exercer os processos educacionais. Se isso se efetiva, entendemos, a partir de Freire (1996), que a educação sai do primado tradicional e bancário, e caminha para a realidade, adquirindo um tom emancipatório e transformador.

Concluímos essa subseção do texto destacando que, para as professoras participantes do estudo, a formação continuada tem somado ao seu trabalho docente. Sua prática profissional em sala de aula tem-se feito em outros domínios. Assim, validamos que os processos educativos vividos por elas (na formação continuada) são significativos e despertam novos conhecimentos e saberes a respeito do ensinar e do aprender.

\section{Limites da formação continuada de professores da Educação Básica do campo}

Nesta última subseção, finalizamos a análise relacionada ao questionário utilizado como técnica de produção de dados com as professoras da pesquisa. No referido momento, abordamos três questões condizentes ao eixo temático "limites da formação continuada de professores da Educação Básica do campo" e uma questão complementar, que visa aprofundar o todo da análise.

Em relação à primeira questão, indagamos se as práticas de formação continuada vivenciadas pelas professoras se associavam ao trabalho docente na Educação do Campo. Seus depoimentos se apresentam na sequência:

Quanto à minha atual formação, não há essa diferenciação entre educação do campo e zona urbana. Os limites encontrados são os poucos recursos de acessibilidade, decorrente ao meio sociocultural e econômico onde os educandos estão inseridos. Porém, os conteúdos metodológicos são 
adaptados de acordo com as especificidades de cada indivíduo (Docente "A", Escola Municipal, Assentamento Favela, Mossoró-RN, 2019).

Na maioria das vezes sim, já que as capacitações se referem ao campo. Geralmente elas buscam retratar a realidade sobre os cuidados com o meio ambiente e implantação de novas tecnologias (Docente "B", Escola Municipal, Assentamento Favela, Mossoró-RN, 2019).

Diante do exposto, alertamos que a formação continuada vivida pelas docentes participantes do estudo não está condizente com a perspectiva de Educação do Campo enfatizada no Brasil pelo Movimento Nacional de Educação do Campo. Segundo Caldart (2012), a formação de professores para a Educação do Campo não pode ser vista como adaptação, como algo externo à realidade dos sujeitos do campo (GENARO; MENDES; CHELOTTI, 2014). Na história, a adaptação foi uma forte marca da educação ofertada aos sujeitos do campo (MEDEIROS, 2019; SANTOS; ARAÚJO, 2019).

Nosso entendimento segue essa perspectiva porque, pelo que compreendemos, a Docente "A" vê que não há diferença na prática de formação continuada vivida se destinar à atuação no campo ou na cidade. Há uma homogeneização das ações desenvolvidas. Já a Docente "B" afirma que, na maioria das vezes, a formação continuada experienciada se reporta indiretamente à Educação do Campo, uma vez que abrange temas relacionados ao campo - meio ambiente.

De forma geral, percebemos que a discussão sobre a Educação do Campo vivida na formação continuada das professoras é tratada com superficialidade, pois não há, no discurso delas, apontamentos acerca do que seja (movimento nacional de educação) e de como se constitui (no diálogo entre educação e comunidade), bem ainda dos principais sujeitos que a desenvolvem (movimentos sociais do campo).

Sobre a segunda questão, solicitamos que as docentes descrevessem limites experienciados na formação continuada que vivenciaram/vivenciam. Elas pontificam:

São limites como aspectos ambientais, econômicos, sociais, afetivos, psicológicos, emocionais e familiares. Estes fatores como sabemos podem interferir negativamente no processo (Docente "A", Escola Municipal, Assentamento Favela, Mossoró-RN, 2019).

[...] Os limites existem sim, pois na maioria das formações, temos o tempo como limite, pois sempre o nosso tempo em sala de aula tende a ser prejudicado, já que temos que adaptar a formação ao nosso trabalho, entre outros (Docente "B", Escola Municipal, Assentamento Favela, Mossoró-RN, 2019). 
Considerando as declarações das participantes do estudo, avaliamos que as Docentes "A" e "B" abordam limites diversos, os quais muitas vezes prejudicam sua formação. Descrevendo cada registro, esclarecemos que a Docente "A" pontua limites que envolvem os aspectos ambientais, econômicos, sociais, afetivos, psicológicos, emocionais e familiares. A Docente "B" descreve o tempo como limite, visto que conciliar o trabalho na escola com a formação continuada se torna complexo. Complementando a discussão, Candeia (2014, p. 45) lista outros limites que envolvem a formação continuada docente:

a falta de tempo do formando, que geralmente desenvolve outras funções, a descontinuidade dos programas de formação, o não recebimento de uma estrutura adequada torna-se superficial e não produz impacto devido ao curto período de tempo em que acontece por razões políticas e administrativas.

$\mathrm{Na}$ história da formação de professores no Brasil, vemos que os cursos de formação, seja em nível inicial, seja continuada, tiveram como grande desafio a conciliação da formação com o trabalho dos professores. A carga horária diária dos docentes, as inúmeras tarefas e funções que desenvolvem na Educação Básica, entre outros, são limites que se impuseram aos professores. Esse aspecto foi percebido na pesquisa.

No que compele à terceira questão, perguntamos às docentes a respeito de como os limites vivenciados na formação continuada influenciam sua atuação docente na escola. Elucidamos, na sequência, suas declarações:

De certa forma sim. Porém, é muito significativa e importante [Formação Continuada] para refletirmos sobre nossa prática pedagógica, [...] ressignificar, inovar no processo ensino-aprendizagem, [...] esses conhecimentos são repassados e pensados para todo contexto escolar (Docente "A", Escola Municipal, Assentamento Favela, Mossoró-RN, 2019).

Com certeza sim, mesmo trazendo benefícios. Pois a partir do momento que os cursos ocorrem em nosso horário de trabalho, isso vai gerar um atraso no desenvolvimento do nosso trabalho, mesmo havendo planejamento, já que a ordem cronológica foi afetada (Docente "B", Escola Municipal, Assentamento Favela, Mossoró-RN, 2019).

Das declarações das professoras, pensamos que o limite do tempo se implica também na sua atuação na escola. Acreditamos que, por falta de tempo, seu trabalho na instituição pode ocorrer sem o devido planejamento das aulas, o que impacta no desenvolvimento de suas ações na escola. 
Se a formação continuada não for desenvolvida considerando as condições espaciais, psíquicas, sociais, culturais, econômicas e políticas dos professores, pensamos que tal prática não contribuirá para o desenvolvimento pleno do profissional em formação (SILVA, 2019), característica percebida na pesquisa.

Como questão final (questão complementar), indagamos a respeito de as docentes pensarem ser importante a formação continuada para atuação na Educação do Campo. Elas aludiram:

Sim, nesse sentido, a formação continuada deve constituir-se como um espaço que possibilite a troca de diferentes saberes, de repensar e refazer a prática do professor, havendo uma reorganização de suas competências e produção de novos conhecimentos (Docente "A", Escola Municipal, Assentamento Favela, Mossoró-RN, 2019).

É de grande importância, já que nos possibilita e capacita-nos a melhorar o processo ensino-aprendizagem na área rural, que é bastante prejudicado devido à distância. Pois, devido a isso, temos que enfrentar problemas de transportes, localização e novas tecnologias, já que o deslocamento à área rural é quase impossível, por conta do acesso a essas comunidades (Docente "B”, Escola Municipal, Assentamento Favela, Mossoró-RN, 2019).

$\mathrm{Na}$ nossa percepção, as docentes veem como relevante a formação continuada com foco na Educação do Campo. Todavia, declaramos, nesse momento, que, por não serem da própria comunidade, há dificuldades de associar as demandas da comunidade com a formação continuada em que participam/participaram.

Outra vez, declaramos que a Educação do Campo apresenta especificidades. Validando esse raciocínio, a formação de seus professores deveria estudá-la, problematizá-la e compreendê-la. Não pesar esse aspecto é, para nós, reproduzir a perspectiva de educação urbana historicamente desenvolvida na educação no meio rural, dessa vez, no contexto da formação continuada de professores.

Concluímos, ressaltando que a formação continuada tem grande importância para a transformação do ensino na Educação do Campo. No contexto referendado, vemos também a contribuição para a educação no semiárido. Assim, compreendemos que ela é um processo permanente de formação fundamental ao trabalho profissional dos professores e também para a transformação da educação. 


\section{Considerações finais}

Esse escrito registrou uma pesquisa que teve como objetivo principal "compreender como se desenvolve a formação continuada de professores dos anos iniciais do Ensino Fundamental de uma escola municipal situada no Assentamento Favela, Mossoró-RN”. Assim sendo, para as participantes da pesquisa, a formação continuada é essencial ao trabalho profissional que desenvolvem na Educação Básica no campo, uma vez que é por meio da formação continuada que o profissional constrói diferentes saberes e amplia o horizonte de suas práticas educativas e pedagógicas na escola.

Como síntese da análise, auferimos que a formação continuada das professoras ocorre por intermédio de cursos ofertados pela rede municipal de ensino, o que está de acordo com a legislação educacional brasileira. Porém, é preciso rever esse aspecto, haja vista que não percebemos o desenvolvimento de ações que se configurem como formação continuada no âmbito escolar das docentes. Entendemos, de acordo com a análise, que a oferta da formação continuada pelo sistema municipal de educação permite que as professoras dialoguem e interajam com mais profissionais da área de educação e, dessa forma, com a realidade educacional mais ampla. Todavia, na investigação, pudemos pensar que tal característica limita o estudo de problemas educacionais que envolvem o contexto de trabalho das docentes, a exemplo do trabalho com turmas multisseriadas.

Em relação ao trabalho das docentes, ainda apontamos que a formação continuada proporciona que elas pensem de forma reflexiva sobre sua prática. Vimos, a partir de seus registros, o desenvolvimento de novas metodologias em seu trabalho pedagógico (como a inclusão das novas tecnologias da informação e comunicação, o trabalho com seminários e aulas interativas), aspecto que consideramos como um avanço na educação. Em um dos registros, chamou-nos a atenção o trabalho educativo com o caráter interdisciplinar.

Como um dos limites da formação continuada que merece atenção neste momento, nos foi relatado o tempo para a conciliação das ações de formação continuada com o trabalho docente na escola. Essa realidade não é incomum a muitos professores no Brasil.

No tocante à Educação do Campo, infelizmente, constatamos que a formação continuada vivenciada por elas, até então, não se faz validando o contexto da Educação do Campo no país. Entendemos que não há um alinhamento com a discussão arrolada nos últimos anos pelo Movimento Nacional de Educação do Campo. Lembramos que, nos cursos de formação continuada, vivenciados pelas participantes da pesquisa, há ações específicas que 
abordam questões da educação, as quais se aproximam da Educação do Campo (educação ambiental, o trabalho com cisternas, entre outros), porém, não atendem ao Movimento, pois temas como a relação entre educação, comunidade e movimentos sociais do campo não são abordados. O que vemos é que a Educação do Campo é inserida de cima para baixo, de modo superficial, não havendo um diálogo com a comunidade local, nem o estudo de seus problemas educacionais.

Em linhas finais, concluímos esse trabalho reforçando que ele pode colaborar para o desenvolvimento de novas pesquisas, bem ainda na formação dos sujeitos que o leem. A formação continuada, pelo que foi abordado no texto, é um tema importante nos estudos educacionais, merecendo atenção pelos pesquisadores da área de educação.

\section{Referências}

ALVORADO-PRADA, L. E.; FREITAS, T. C.; FREITAS, C. A. Formação continuada de professores: alguns conceitos, interesses, necessidades e propostas. Diálogo Educacional, Curitiba, v. 10, n. 30, p. 367-387, maio/ago. 2010. Doi: 10.7213/rde.v10i30.2464. Disponível em: https://periodicos.pucpr.br/index.php/dialogoeducacional/article/view/2464. Acesso em: 15 maio 2020.

AMADOR, J. T. Concepções e modelos da formação continuada de professores: um estudo teórico. Humanidades e Inovações, Pará, v. 6, n. 2, p. 151-167, 2019. Disponível em: https://revista.unitins.br/index.php/humanidadeseinovacao/article/view/862. Acesso em: 15 maio 2020.

BRASIL. Ministério da Educação. Lei de Diretrizes e Bases da Educação Nacional. Lei no 9.394, de 20 de dezembro de 1996. Estabelece as diretrizes e bases da educação nacional. Brasília, DF, 1996.

BRASIL. Ministério da Saúde. Conselho Nacional de Saúde. Resolução CNS, no 510, de 07 de abril de 2016. Disponível em: http://conselho.saude.gov.br/resolucoes/2016/Reso510.pdf. Acesso em: 28 maio 2020.

CALDART, R. S. Educação do campo. In: CALDART, R. S. et al. (org.). Dicionário da Educação do Campo. São Paulo: Expressão Popular, 2012. p. 259-267.

CANDEIA, V. A. D. A formação continuada de professoras: repercussões na prática docente. 2014. 131 f. Dissertação (Mestrado Profissional em Formação de Professores). Universidade Estadual da Paraíba, Campina Grande, 2014.

DALBEN, A. I. L. F. Concepções de formação continuada de professores. In: FÓRUM PERMANENTE DE FORMAÇÃO CONTINUADA DE PROFESSORES, 2004. Disponível em: https://www.ufmg.br/proex/forumpfcp/artigo1. Acesso em: 15 maio 2020. 
FREIRE, P. Pedagogia da autonomia: saberes necessários à prática educativa. 24. ed. Rio de Janeiro: Paz e Terra, 1996.

FREITAS, A. S. A questão da experiência na formação profissional dos professores. In: FERREIRA, A. T. B.; ALBUQUERQUE, E. B. C.; LEAL, T. F. (org.). Formação continuada de professores: questões para reflexão. Belo Horizonte: Autêntica, 2007. p. 3350 .

FURTADO, J. A importância da formação continuada dos professores. 2015. Disponível em: juliofurtado.com.br/2015/07/22/a-importancia-da-formacao-continuada-dos-professores/. Acesso em: 15 abr. 2020.

GARCIA, M. C. Desenvolvimento profissional docente: passado e futuro. Revista de Ciências da Educação, Lisboa, n. 8, p. 7-22, jan./abr. 2009. Disponível em: http://sisifo.ie.ulisboa.pt/index.php/sisifo/article/view/130. Acesso em: 10 abr. 2020.

GATTI, B. A. Formação continuada de professores: a questão psicossocial. Cad. Pesqui., São Paulo, n. 119, p. 191-204, jul. 2003. Doi: 10.1590/S0100-15742003000200010. Disponível em: https://www.scielo.br/j/cp/a/ZvqbCbK3qV6kNR54KvQ4Cwr/abstract/?lang=pt. Acesso em: 18 mar. 2020.

GATTI, B. A.; BARRETTO, E. S. S. Professores do Brasil: impasses e desafios. Brasília: Unesco, 2009.

GENARO, F.; MENDES, H. N.; CHELOTTI, M. C. A educação do campo no contexto da formação continuada de professores. Revista de Educação Popular, Uberlândia, v. 13, n. 1, p. 53-66, jan.-jun. 2014. Doi: 10.14393/REP-v13n12014-art04. Disponível em:

http://www.seer.ufu.br/index.php/reveducpop/article/view/26916. Acesso em: 18 abr. 2020.

IMBERNÓN, F. Formação docente e profissional: formar-se para a mudança e a incerteza. 8. ed. São Paulo, 2010.

KENSKI, V. M. Tecnologias e ensino presencial e à distância. 9. ed. Campinas, SP: Papirus, 2013.

MACIEL, L. S. B.; SHIGUNOV NETO, A. (org.). Formação de professores: passado, presente e futuro. São Paulo: Cortez, 2004.

MEDEIROS, E. A. Formação interdisciplinar de professores: estudo pedagógico-curricular sobre a Licenciatura em Educação do Campo da Universidade Federal Rural do Semi-Árido. 2019. 661 f. Tese (Doutorado em Educação) - Universidade Estadual do Ceará, Fortaleza, 2019.

MEDEIROS, E. A. A interdisciplinaridade na educação: uma abordagem conceitual. Linguagens, Educação e Sociedade, Teresina, v. 23, n. 39, p. 158-177, maio/ago. 2018. Doi: 10.26694/les.v0i39.7197. Disponível em:

https://revistas.ufpi.br/index.php/lingedusoc/article/view/7197. Acesso em: 18 abr. 2020.

NÓVOA, A. Formação de professores e profissão docente. In: NÓVOA, A. (org.). Os professores e a sua formação. Lisboa: Dom Quixote, 1992. p. 15-34. 
PIMENTA, S. G.; GHEDIN, E. (org.). Professor reflexivo no Brasil: gênese e crítica de um conceito. São Paulo: Cortez, 2002.

PIMENTA, S. G.; LIMA, M. S. L. Estágio e docência: diferentes concepções. Poíesis Pedagógica, v. 3, n. 3-4, p. 5-24, 2006. Doi: 10.5216/rpp.v3i3e4.10542. Disponível em: https://www.revistas.ufg.br/poiesis/article/view/10542 . Acesso em: 15 maio 2020.

SANTOS, J. B.; ARAUJO, E. J. M. A educação do campo no campo da educação popular. Revista de Educação Popular, Uberlândia, v. 18, n. 3, p. 56-73, 2019. Doi: 10.14393/REP-v18n32019-48761. Disponível em: http://www.seer.ufu.br/index.php/reveducpop/article/view/48761. Acesso em: 18 abr. 2020.

SILVA, M. L. Pedagogia freireana na perspectiva da educomunicação popular. Revista de Educação Popular, v. 18, n. 3, p. 4-19, 2019. Doi: 10.14393/REP-v18n32019-48040.

Disponível em: http://www.seer.ufu.br/index.php/reveducpop/article/view/48040. Acesso em: 18 maio 2020.

TARDIF, M. Saberes docentes e formação profissional. 11. ed. Petrópolis, RJ: Vozes, 2010.

Submetido em 4 de junho de 2020.

Aprovado em 21 de setembro de 2020. 